Williams CS and Saunders MNK (2006) Developing the Service Template: From

measurement to agendas for improvement Service Industries Journal 26.5, 1-15

\title{
DEVELOPING THE SERVICE TEMPLATE PROCESS: FROM MEASUREMENT TO AGENDAS FOR IMPROVEMENT
}

\section{ABSTRACT}

Traditional survey based measures of service quality are argued to be problematic when reflecting individual services and turning measurement into action. This paper reviews developments to an alternative measurement approach, the Service Template Process and offers an extension to it. The extended process appears able to measure service users' and deliverers' perceptions of service quality independently. It also enables participants to jointly agree an agenda for quality improvement. The extended process is evaluated in four service situations. The paper concludes with an assessment of the advantages and disadvantages of the process in comparison with more traditional, approaches to measuring service quality.

Keywords: Service quality; Service Template Process; process consultation; quality improvement 


\section{INTRODUCTION}

As commitment to quality improvement becomes an essential ingredient of sustained competitive advantage, service managers are forced to contend increasingly with issues of service quality measurement [O'Neill and Palmer, 2001]. Whilst there is no shortage of views on survey-based instruments such as SERVQUAL, [Parasuraman, et al. 1985], for measuring service quality and customer satisfaction, there is less debate about the usefulness of such traditional measures as diagnostic tools for remedial action. Discussion regarding the subsequent development of agendas for action is also less evident. Indeed, Johnston [1999] highlights a reluctance to review critically and develop service performance measurement systems, highlighting examples of the performance measures per se being the focus of attention, rather than the improvement activities flowing from them.

This paper reviews the development of an alternative approach for measuring service quality, the Service Template Process [STP] [Staughton and Williams, 1994] and evaluates the ability of its subsequent extension to measure quality and enable agendas for service quality improvement. We commence with an overview of traditional approaches to service quality measurement, in which issues associated with generic measures and data interpretation are highlighted. This is followed by a review of the development of the STP. In this, we emphasise a need for systematic evaluation of the process and make suggestions for its extension to allow the development of quality improvement agendas. The Extended Service Template Process [ESTP] is evaluated subsequently in four different service situations: the main reception of a large, multi-site, public-sector organisation; dissertation supervision at a new university business school; the author-publisher relationship in an international publishing company; and mentor training for a small business support service provider. 
Within the evaluation, particular attention is given to the extent to which facets of the service encounter considered important by service users and deliverers are measured, the development of shared understandings and the process's utility in leading to quality improvement agendas. The paper concludes with an assessment of the advantages and disadvantages of the ESTP relative to traditional measures of service quality.

\section{TRADITIONAL APPROACHES TO MEASURING SERVICE QUALITY}

Traditional survey-based approaches to measuring service quality or customer satisfaction such as SERVQUAL [Parasuraman, et al. 1985,] measure the gap between service users' perceptions and expectations across a series of standardised dimensions characterising the service. Notwithstanding shortcomings of conceptualising service quality in this manner, recognised for example in the SERVQUAL debates [Carman, 1990; Cronin and Taylor, 1992], the use of the disconfirmation approach is reported widely in the literature [Parasuraman, 1995; Robinson, 1999].

Carman [1990] argues that constructs representing service quality are a function of a particular service and the industry within which it is located. Carman [2000] also confirms that different users of a service may assign different levels of importance to the same quality dimension. Furthermore, the use of generic constructs to measure a particular service's quality may not provide the details necessary to define the specific causes of a problem rather than its symptoms [Kilmann, 1986]. Generic constructs may therefore fail to account for the uniqueness and realities of specific services, and how these are expressed and interpreted by the parties involved. Furthermore, where these measures are used only from the perspective 
of service user or deliverer, any problems identified are unlikely to reflect fully the dyadic nature of service encounters. [Svensson, 2001]

If the measurement of service quality is to lead to improvement, data collected must be useful. In this context, usefulness can be viewed from three interrelated perspectives. The first emphasises the suitability of the constructs used to capture perceptions of reality considered important by each party involved within the specific service [Chi Cui et al., 2003], in other words construct validity. The second perspective relates to the implications of the sufficiency of detail in respect of a clear understanding of the particular service situation. Kilmann [1986: 131] summarises this as the need to 'define problem causes rather than just symptoms'. The third is concerned with the extent to which these data enable meanings to be understood and explored and quality improvement agendas derived.

Problems of second order interpretation [Yin, 2003] can occur when data collected using measures of service quality are subject to interpretation by third parties, such as consultants or managers. The meanings ascribed to the data by the interpreter may differ from those given by service users or deliverers, leading to inconsistency in interpretation. A person undertaking an inquiry may have filtered and added her or his own understanding to the language used and emphases placed by respondents, rather than it being understood and interpreted as intended [Foddy, 1994]. Consequently, meanings in the data may be lost, or at best, mis-reported. Furthermore, traditional approaches do not normally require respondents to indicate the relative importance of quality constructs [Pitt et al., 1995]. Such analyses usually involve the person undertaking the inquiry judging what is important, concentrating attention on those areas that she or he believes are of critical concern [Foddy, 1994; Krueger, 1994]. 
Consequently, her or his judgement about which characteristics are key to the quality of service forms the basis for analysis and future action.

\section{AN ALTERNATIVE APPROACH: THE DEVELOPMENT OF THE SERVICE TEMPLATE PROCESS}

The STP has been developed incrementally over the past decade through a series of consultancy interventions. Throughout this, the core of the process has been the generation of visual representations of a defined service, or Service Templates, by groups of service users and deliverers. Each Template now records separately the characteristics of a service identified as important by the group that created it and, for each characteristic, perceptions and expectations measured against a group-defined Likert type scale anchored by 'ideal' and 'worst' situation descriptors [fig. 1]. During the STP's development new aspects have been incorporated in response to emergent needs of clients. This has resulted in a process that not only measures service quality, but also reflects the dyadic nature of service encounters and the need to promote action to improve service quality. It is to these developments that we now turn.

Ideal place for fig. 1

\section{The original Service Template Process}

Staughton and Williams' [1994] STP was developed to illustrate the 'fit' between the capabilities of an operation and the needs of its market[s]. The approach acknowledged the 
uniqueness of each specific service, allowing definition of those aspects [characteristics] users believed were important and highlighting gaps between perceptions and expectations. As part of the process, data were elicited from some form of sample of market[s'] representatives or service users and recorded visually as a Service Template. This measured the service in terms of the perceptions and expectations of characteristics specific to the market[s] [table 1, phase II]. However, by focussing on users, data collected could only be used to analyse the service from one perspective rather than reflecting its dyadic nature.

\section{Ideal place for table 1}

\section{Participant selection, service quality measurement and data validation}

Subsequent development of the STP [Staughton et al., 1997; Williams et al., 1999], focused upon sample selection and the need to reflect the bi-directionality of service encounters in the measurement of service quality [table 1, phases I and II]. In phase I, purposive samples were now drawn from each party involved in a service, individuals being selected on the basis of their criticality to that service. These, they argued, enabled the diversity and key dimensions of the service to be explored and logical generalisations made regarding the key themes.

Service quality measurement and data validation [table 1, phase II] developed the 1994 process to allow independent collection of data from each party. Separate meetings of approximately two hours duration were organised with each party, the number of participants [six to ten] having been informed by Krueger's [1994] work on focus groups. Each meeting progressed through four stages. In the preparation stage, the facilitator explained the purpose and nature of the process and clarified meanings of terms. The actual service situation being 
considered was displayed prominently to help maintain focus. The characteristics of this situation were then elicited and displayed in the order they emerged, by the facilitator using the group's words, through a brainstorming type process [stage 2]. Clarification of meanings was sought; thereby ensuring that everyone had a similar frame of reference and the same understanding. Subsequently, the list of characteristics was refined and ideal and worst situation descriptors [bi-polar adjectives] generated for the extremes of each characteristic [fig.1]. Perceptions and expectations of the service and variations within these were then measured and plotted for each characteristic relative to the extremes using a ten-point scale, the value ten representing the ideal and the value one, the worst case [stage 3]. Williams et al. [1999] comment that the resultant Service Template [fig. 1], typically including 20 and 30 characteristics, was then discussed with participants to help confirm internal validity. At the end of this stage [4] participants identified and weighted those characteristics they considered most important by allocating 100 points between them.

The developments outlined above resulted in each party measuring and recording those characteristics of a service's quality they considered important as a separate Service Template. This, Williams et al. [1999] argued, addressed several of the shortcomings of more traditional, approaches to measuring service quality. Unlike SERVQUAL, or similar instruments, the constructs [characteristics] against which perceptions and expectations were measured and recorded on each Template were neither generic nor specified. Rather, as part of the process, each party involved in the encounter determined separately those characteristics important to it. Consequently, the resulting Templates reflected the language, terminology, detail and priorities specific to each party. Citing Lewis and Mitchell [1990], Williams et al. [1999] argued the Templates' pictorial displays were easy for managers to understand and use. 


\section{Improvement agenda development}

In a further development, Williams et al. [1999] incorporated a follow-up meeting in the STP involving all parties who had generated Service Templates. This was to allow participants to explore each other's Templates in 'a spirit of enquiry, in particular to learn about the relationship rather than judge or defend it' [Williams et al., 1999: 375]. Whilst allowing consideration of both service users' and deliverers' views and offering potential for greater understanding of the service, it did this only superficially. Consequently there was a need to develop this final phase [III] to enable differing perspectives to be explored in greater depth, understood and, where necessary, reconciled as well as facilitate the development of an agreed improvement agenda. In addition there was a need to evaluate the utility of the entire process.

\section{The relevance of a process consultation framework}

Organisational development research had highlighted the importance of problem ownership for those developing appropriate solutions, a key aspect of phase III. In particular, Schein [1999] emphasises the significance of process management to enable insights by those involved, but also argues that a consultant will never know sufficient about particular situations to be able to make specific recommendations. Subsequent to an effective helpingrelationship having been developed, a client and consultant can work together to choose appropriate processes to understand the situation, define problems and develop solutions, which the client owns. Thus, rather than a third party interpreting the data and providing solutions, the role of what Schein [1999] terms the 'process consultant' is to help the client in 
this process. Where agreed with the client, using an extension of the STP within a process consultation framework might:

permit the client to perceive, understand and act on the process events that occur in the client's internal and external environment in order to improve the situation as defined by the client [Schein 1999: 20].

This could enable the development of an agreed quality improvement agenda.

These ideas informed the development of phase III of the STP in which users and deliverers met and explored jointly each other's views of the service and developed an improvement agenda [table 1]. The meeting commenced with participants being reminded of the process to date and the purpose of the meeting, namely to share explore, learn and identify possible actions [phase III, stage 1]. Drawing upon Schein's [1999] work, the Service Templates created in phase II became visual catalysts for these users and deliverers to explore and learn about each other's perceptions and expectations [phase III, stage 2]. This was facilitated by a process consultant, focusing upon sharing these Templates, prior to establishing and understanding jointly which characteristics were important for the service's quality and why. The composition of groups and the content of their discussions were determined by the participants to help maintain their ownership of the process. Finally, participants were asked to reflect on the meeting and focus upon actions needed to improve service quality [phase III, stage 3]. To help provide structure, feedback from participants was sought by the process consultant adopting the role of confrontive enquirer [Schein, 1999]. Through this participants identified and owned an agenda to improve service quality.

The resultant ESTP builds upon the measurement and presentation aspects of Staughton and Williams' [1994] work and its subsequent developments [Staughton et al., 1997; Williams et 
al., 1999]. Setting the STP within a process consultation framework could help ensure ownership of both the process and outcomes, enabling participants to understand and where necessary, reconcile their own and others' views prior to jointly generating a service quality improvement agenda. Following a description of the research method, the remainder of this paper evaluates the ESTP, paying attention to both measurement and the process's utility in the development of service quality improvement agendas.

\section{METHOD}

Evaluation of the ESTP focussed upon two interrelated aspects: measurement, and the process's utility to develop an improvement agenda. To this end, data were collected in four distinct service situations during and after the application of the ESTP. These were the main reception of a large multi-site public sector organisation, undergraduate dissertation supervision at a new university business school, the author-publisher relationship in the English Language Teaching [ELT] division of an international publishing company, and mentor training in a small business support services provider [table 2]. For each case, data were collected during and after the application of the ESTP from both service users and deliverers.

\section{Ideal place for table 2}

Within each case, data collection utilised a combination of research diaries, participant observation, follow-up interviews and written feedback from participants, thereby avoiding too greater reliance on one single technique [Knights and McCabe, 1997]. Consent was obtained from each client to use data for research purposes and ESTP evaluation. For each of 
the cases, one researcher acted as process consultant and the other as observer. The former recorded secondary observations in a research diary and the latter noted primary observations such as participant's interactions, comments and the extent to which they appeared involved, as well as any amendments to the process. At each meeting, participants were introduced to the process consultant and observer and assured of anonymity and confidentiality. Data were collected using this approach at the participant selection [phase I], service quality measurement and data validation [phase II] and the improvement agenda development [phase III] phases of the ESTP [table 1] for all but the author-publisher relationship case. For this case data were collected at phases I and II, the process terminating prior to phase III.

Following phase III, semi-structured group interviews of approximately 30 minutes duration were planned by the observer to capture participants' perceptions of the process and its utility. This was possible for 8 of the 10 reception service participants and all 14 of those considering dissertation supervision. Due to time constraints, participants in the mentor training case were contacted by email, 7 of the 8 responding. Data were also collected approximately 6 months after the completion of the ESTP on its impact within each case study organisation. This was obtained by telephone interview with the senior manager involved [client] and triangulated with additional data collected from at least two of the participants in the ESTP.

From these data we sought to evaluate the measurement process and its utility for improvement agenda development. Initially we explored each of the four cases separately, thereby helping to ensure that insights into the contextual realities of each service situation were retained [Dyer and Wilkins, 1991]. For each case we analysed and triangulated the data collected independently using the three phases of the ESTP as a framework. Where we varied in our interpretation of these data, we discussed this further prior to agreeing a conclusion. By 
this process problems of reliability associated with single person interpretation were minimised [Miles and Huberman, 1994]. Following Eisenhardt [1989], findings from the four case studies were compared and contrasted subsequently. This allowed a more general assessment of the ESTP's utility in the development of quality improvement agendas to be made.

\section{FINDINGS}

\section{Participant selection}

Within the ESTP the utility of the data collected depends upon the characteristics of the participants selected to generate the Service Templates and their subsequent commitment to the process. Using the ESTP within the process consultation framework focussed the time spent with the client on careful selection of those users and deliverers who should be involved against clear service-specific criteria. Sample selection concentrated on those individuals who could between them account for and explain the extent and diversity of the service in question. Working with each of the four cases revealed that, to ensure the collection of useful data, the number of participants within each group could need to deviate from the range previously suggested [Williams et al., 1999]. For example, in the publishing company, the client revealed that she was aware of the differing needs and experience of new and experienced authors [service users]. Author samples were therefore stratified into two groups to reflect this, the two service deliverer samples consisting of those commissioning editors currently working with these authors [table 2]. In contrast in the dissertation supervision case, discussion with the module leader emphasised a need to focus upon overall quality of dissertation supervision. Consequently, the purposive sample of service users consisted of eight students taking a level III dissertation who represented all degree combinations within 
that business school, whilst the six supervisors [service deliverers] encompassed a wide range of supervisory and subject experience [table 2].

In all but one case [mentor training], the projected time requirements of the ESTP, whereby individuals are requested to attend two meetings each of approximately 2 hours duration, resulted in a need to replace some of the initial sample with equivalent people. The time requirement also had implications for other phases of the process, which are discussed later.

\section{Service quality measurement and data validation}

Subsequent service quality measurement and data validation emphasised the importance of the preparation stage [table 1: Phase II, stage 1]. In all but the reception service case, between 10 and 15 minutes were devoted to explaining the nature and operation of ESTP in relation to a neutral example of a familiar service encounter, a supermarket checkout. Observer notes confirmed that this resulted in fewer questions of clarification and justification during the creation of the Service Templates for these cases. Despite this, the observer noted that, in all four cases, participants often appeared sceptical at the start of the ESTP, needing to experience and understand the process as applied to their service situation before committing themselves. Research diary comments by the process consultants support this, a typical comment, relating to the managers of the small business support service, being: 'Managers seemed to only tolerate the process until plotting perceptions and expectations, then they came alive'. Only one individual withdrew entirely from phase II of the process.

In exploring a service's characteristics and the 'ideal' and 'worst' descriptors, participants tended initially to offer single adjectives, the 'ideal' being expressed as the opposite to the 
'worst'. For example, the ideal for characteristic 'Environment -noise' [fig. 2a] was originally 'quiet', the worst being 'noisy'. For each characteristic the process consultant asked participants to clarify the adjectives' meanings. This often resulted in discussion and revision to a short description participants felt captured better the nature of that particular characteristic, in this instance 'soft and absorbed' and 'echoes'. Occasionally where participants questioned the precise meanings of particular characteristics, two sets of descriptors were generated for the same characteristic. For example, the extremes for 'Information provision - range' [fig. 2a] are 'from all areas' and 'limited', as well as 'regular and on-off' and 'sporadic', suggesting that both the frequency and origins of the range of information provision are significant to this group's definition of service quality. The observer noted that, as the process progressed participants' confidence in developing their own descriptors grew, meanings often being clarified unprompted.

\section{Ideal place for fig. 2}

For all cases, participants understood and liked the visual representation of service quality in their Service Templates and the interactive process of plotting perceptions and expectations against their identified characteristics [for example, fig. 2]. They also liked the flexibility within the process, a typical comment being 'it allowed us to say what we thought was important'. The observer noted that, within each group, participants used this stage to explain and justify their perceptions to each other. They appeared surprised but pleased that the process was sufficiently flexible to measure and record within-group differences, as typified by one of the trainee small business mentors who, prior to reassurance from the consultant, asked 'are you sure it's alright for us to have different perceptions?' Through this process all gained an understanding of their group's perceptions and expectations across their agreed characteristics. 
The final stage of this phase allows each group to weight the characteristics, thereby highlighting those considered most important. All but one group approached this by allocating 100 points, the managers of the small business support service provider preferring to rank the characteristics. The most common approaches to allocating points were group discussion or calculating the mean of group members' individual points allocations. Four groups, including receptionists and reception service users [fig. 2], chose to use points in multiples of five. Furthermore, participants sometimes grouped characteristics prior to their weighting to emphasise interdependence. This was particularly evident for the receptionists' characteristics relating to the 'receptionist' and the 'reception desk' [fig 2b]. Observer notes and research diary comments highlighted the difficulty participants experienced in agreeing and prioritising important characteristics. However, the resulting discussions helped each group further validate their measurement of service quality, minor changes being made where requested.

The time taken to generate each of the 12 Service Templates ranged from 85 minutes for the single small business mentor trainer to 165 minutes for the three receptionists [table 2], the mean time being 125 minutes. For some participants, particularly those in more senior roles, this created problems, where they had only allowed the two hours requested. Immediately after each meeting, individual Templates were word processed, the characteristics being presented in weighted order, emphasising those that were considered most important. Subsequently they were emailed to group members to check for accuracy.

\section{Improvement agenda development}


The improvement agenda development phase [table 1] took place in three of the cases. The Publishing Company argued that the time and resource requirements were too great; consequently the process consultant undertook interpretation. For the remaining three cases, there were difficulties in finding time when all those involved in generating the associated Service Templates were available. Meetings were held up to two months after these Templates had been generated and, other than for dissertation supervision, did not include all participants. Although, appearing to have little impact on the interpretation of the Templates, the time delay between phases II and III meant participants welcomed the opportunity to refamiliarise themselves with their Templates prior to discussion.

Following assurances of confidentiality and anonymity, Service Templates were explored jointly. Comments made by participants suggest this enabled the development of shared understanding of the range of views. Discussion was introduced by short presentations from each group explaining their Templates, concentrating on the high-weighted characteristics. Each participant received copies of all Templates and necessary clarifications were sought. Subsequently, for each case participants chose to discuss and explore the Templates collectively, focusing on the major differences and similarities of the high weighted characteristics and the gaps between perceptions and expectations, rather than precise values suggested by the numbers on the ten-point scale.

For some cases, such as the reception service, there was a high degree of commonality between all groups, regarding the characteristics determining service quality. Discussion emphasised how the receptionists' characteristic 'Quality of time with users' and the users' characteristics: 'Role-switchboard' and 'Role-counter' [fig. 2] highlighted the conflict presented by the demands of simultaneously operating the main switchboard and providing 
customer service. Similarly, the receptionists' 'knowledge' was a common concern, as was the Reception environment. Users identified the latter as 'Environment -noise' and deliverers as 'Reception desk -acoustics'. For both, gaps between expectations and perceptions indicated a need for considerable improvement. Despite apparent differences in language, the receptionists commented that the process was 'good, because all groups had raised the same issues'.

Participants in the three cases confirmed that, although time consuming, joint exploration of the Service Templates was worthwhile, providing an opportunity for dialogue leading to jointly agreed service quality improvement agendas. The descriptors of each characteristic provided an additional level of detail to inform this process. For example, in the case of the need for simultaneous delivery of customer service and switchboard operation, receptionists' concerns centred on the attention deserved by service users, as reflected in their descriptors 'all your attention' and 'begrudged time' for the characteristic 'Quality of time with users'; [fig. 2b]. Reception users focused on queues with extremes of 'available to caller' and 'engaged' and 'quickly available to visitor' and 'queues' respectively for their characteristics: 'Role-switchboard' and 'Role-counter' [fig. 2a]. Joint exploration of these detailed issues led to proposals of how these operations could be separated to the address both concerns. Participants commented that discussion allowed them to explain those aspects of the service where expectations were not met in sufficient detail to enable the associated problems to be defined clearly and for them to suggest possible improvements. Student participants and trainee small business mentors commented that they had enjoyed working with their supervisors or managers to develop quality improvement proposals. They said that they found the process 'engaging' and that, unlike more traditional methods of evaluation they had experienced, felt their 'contributions were really valued'. 
These meetings required careful facilitation by the process consultant to help focus dialogue on both learning and possible improvements, as well as sufficient time for meaningful discussion and reflection. The time required for each of the three meetings varied from a time-limited meeting of 65 minutes for mentor training, through 120 minutes for dissertation supervision, to 155 minutes for the reception service.

The process' utility in enabling service quality improvement agendas to emerge can be considered in relation to the use made of the data generated by these organisations. In the case of the reception service, participants drew up jointly a list of issues and possible solutions. One resulting outcome was the relocation of the main switchboard away from the reception area to address the perceived conflict in the receptionists' role. The receptionists commented that they wished to continue to be involved in further improvements. In the case of dissertation supervision, the timing of the research methods workshops, consistency of the supervisory process and assessment criteria were the main issues arising from phase III of the ESTP. As a result, the workshops were rescheduled to reflect more closely the stage students should have reached in their dissertations. Additionally, consistency of advice was the subject of a staff development session where lecturers reconsidered the nature of the dissertation and assessment criteria. Outcomes of the ESTP within the small business support services provider focused upon the characteristics required of small business mentors. The importance of empathy for small business mentors, a need for them to be able to 'speak the same language' and a commitment for regular contact with small business clients were highlighted and subsequently incorporated into the support programme. In addition, suggestions were made to address the trainee mentors' comment that an MBA was a useful rather than an essential requirement for small business mentors. 
In contrast, although examination by the process consultant of the Service Templates of the author-publisher relationship resulted in reported recommendations, these did not appear to be owned by the organisation. The report suggested that, although commissioning editors perceived their relationship with authors to be successful, there were aspects authors felt needed improvement; it also emphasised that both parties needed to be made aware of each other's views. Although a follow-up telephone interview emphasised this would be addressed, what was done was unclear.

\section{DISCUSSION}

Drawing upon purposive samples of parties involved in a service, the ESTP has been shown to enable the characteristics that each party believes are important to the quality of that service to be established and defined separately. Perceptions and expectations of performance have been measured and recorded in a visual format relative to participant-defined and described descriptors. The resulting Service Templates have provided a context for enabling joint understanding, problem definition and the development of an agenda for action.

Like the STP, the ESTP measures and records gaps between perceptions and expectations on a separate Service Template for each group. However, phase III of the ESTP enables these Service Templates to be compared and discussed by all participants in the process, as they reexamine those characteristics they believe are important to that service's quality in conjunction with the characteristics highlighted by the other party. Participant generated characteristics and descriptors afford a high level of service specific detail as a context for this 
discussion. Visual representation in the form of Service Templates appears to assist participants' understanding of their own and other group's views in this process.

Discussion means each party tests and defends the values and norms on which those characteristics they believe to be important are based. Despite an apparent lack of commonality in the language used to define a service, for example the reception service, there were often elements of common ground regarding those characteristics that were important. Where this was not so, for example aspects of dissertation supervision and the authorpublisher relationship, the Service Templates emphasised that the parties measured service quality within differing sets of norms. The ESTP therefore enables those critical to service delivery and usage to reflect upon the norms underlying their own assessments of service quality and their appropriateness in relation to other service participants. By highlighting differences and similarities in the norms and values upon which such assessments are based, new understandings, specific to the service in question are developed by participants. The discursive and participative nature of phase III of the ESTP is instrumental in promoting shared understanding and ownership in the context of the specific service.

Whilst understanding and ownership are the precursors to clear problem definition and an agreed improvement agenda, the role of the process consultant is critical in realising this. She or he must ensure that dialogue between participants focuses on both understanding and developing an improvement agenda, therefore she or he must be able to listen to individuals' contributions, summarise alternative views and judge when to move the process forwards from defining problems to identifying possible improvements. Both the STP and ESTP use participant defined characteristics and descriptors to measure service quality, thereby enhancing the possibility of achieving this. The discursive nature of phase II of the process 
appears to help participants to identify the symptoms of quality issues, which are often reflected in the descriptors of the 'Worst situation' for the relevant characteristic. Discussion, in phase III of ESTP can then be moved beyond these symptoms to focus more readily on the causes of quality issues and development of improvement agendas.

The research reported supports the use of the ESTP within a process consultation framework, the process consultant's role being to assist in the derivation, exploration and subsequent dialogue about the Service Templates and the agreement of agendas for action. Fundamental to the ESTP when measuring service quality is the separate initial involvement of purposive samples drawn from all parties [phase I]. This ensures key dimensions from both service user and deliverer perspectives are surfaced separately measured and recorded in Templates. However, prior to use of the ESTP, a clear understanding and commitment by the client and process consultant to both the process and the time required of individuals involved has been shown to be essential. This understanding incorporates the process of participant selection where the need to ensure the collection of useful data may require deviation from the sample size range suggested.

\section{CONCLUSIONS}

In conclusion, the ESTP is able to reflect the reality of dyadic interchange between the parties involved in any service. It is not intended to provide a statistically representative evaluation. Rather it offers an additional tool to the range of existing quality assessment processes. Like the STP, the ESTP offers an alternative approach to measure service quality in a systematic manner and because predetermined scales are not used, it is likely to be applicable without modification to evaluating quality across a range of service encounters. Although time 
consuming, users and deliverers are able to question and evaluate the appropriateness of the characteristics they believe are important within a service and achieve consistency of understanding. Integral to this process is the need for discussion, learning and problem definition, deriving an agenda for improvement and developing ownership of agreed solutions. The cases outlined suggest the ESTP offers an alternative to measuring of service quality and can assist in improvement agenda development within the arena of service operations. As such, we would contend that it is one response to Johnston's [1999] call for the application of the tools and frameworks to improve service management. Further research is needed to assess this contention across a greater range of service encounters.

\section{REFERENCES}

Carman, J.M., (1990) Consumer perceptions of service quality: as assessment of the SERVQUAL dimensions, Journal of Retailing, 66(1), pp.33-35.

Carman, J.M., (2000) Patient perceptions of service quality: combining the dimensions, Journal of Services Marketing, 14(4), pp.337-352.

Chi Cui, C., Lewis, B.R. and Park, W., (2003) Service quality measurement in the banking sector in South Korea, International Journal of Bank Marketing, 21(4), pp.191-201.

Cronin, J.J. and Taylor, S.A., (1992) Measuring service quality: a re-examination and extension, Journal of Marketing, 56, July, pp.56-68. 
Dyer, W.G. and Wilkins, A.L. (1991) Better stories not better constructs to generate better theory: A rejoinder to Eisenhardt, Academy of Management Review, 16(3), pp. 613-619.

Eisenhardt, K.M. (1989) Building theories from case study research, Academy of Management Review, 14(4), pp.532-550.

Foddy, W. (1994) Constructing Questions for Interviews and Questionnaires, Cambridge: Cambridge University Press.

Johnston, R., (1999) Service operation management: return to roots, International Journal of Operations and Production Management, 19(2), pp.104-124.

Killman, R.H. (1986) Beyond the quick fix: Managing five tracks to organizational success. San Francisco, CA: Jossey-Bass.

Knights, D. and McCabe, D. (1997) How would you measure something like that? Quality in a Retail Bank, Journal of Management Studies, 34(3) 371-388.

Kreuger, R.A. (1994) Focus Groups: a Practical Guide for Applied Research. (2 ${ }^{\text {nd }}$ edition), Thousand Oaks, CA: Sage.

Lewis, B.R. and Mitchell, V., (1990) Defining and measuring the quality of customer service, Marketing Intelligence and Planning, 8(6), pp.11-17. 
Miles, M.B. and Huberman, A.M. (1994). Qualitative Data Analysis. Thousand Oaks, CA: Sage.

O’Neill, M. and Palmer, A., (2001) Survey timing and customer perceptions of service quality, Managing Service Quality, 11(3), pp.182 - 190.

Parasuraman, A., (1995) Measuring and monitoring service quality, in Glynn, W.J and Barnes, J.G., (eds.), Understanding Services Management, Wiley: Chichester, pp.143-177.

Parasuraman, A., Zeithaml, V.A. and Berry, L.L., (1985) A conceptual model of service quality and its implications for future research, Journal of Marketing, 49, Fall, pp. 41-50.

Pitt, F.F., Watson, R.T. and Kavan, C.B., (1995) Service Quality: a measure of information systems effectiveness, MIS Quarterly, June, pp.173-187.

Robinson, S., (1999). Measuring service quality: current thinking and future requirements, Marketing Intelligence and Planning, 17(1), pp.21-32.

Schein, E.H. (1999) Process Consultation Revisited: Building the Helping Relationship, Reading, Massachusetts: Addison-Wesley Longman.

Staughton, R.V.W. and Williams C.S., (1994) Towards a simple, visual representation of fit in service organisations: the contribution of the Service Template, International Journal of Operations and Production Management, 14(5), pp.76-85. 
Svensson, G., (2001) The quality of bi-directional service quality in dyadic service encounters, Journal of Services Marketing, 15(5), pp.357 - 278.

Staughton, R.V.W., Williams, C.S. and Saunders, M.N.K., (1997) Measuring quality in a tripartite service relationship, in Armistead, C. and Kiely, J., Effective Organisations: Looking to the Future, London: Cassell, pp.221-225.

Williams, C.S., Saunders, M.N.K. and Staughton, R.V.W., (1999) Understanding service quality in the new public sector: an exploration of relationships in the process of funding social housing, International Journal of Public Sector Management, 12(4), pp.366-379.

Yin, R. K. (2003) Case Study Research: Design and Methods, ( $3^{\text {rd }}$ edition) Thousand Oaks, CA: Sage. 
Table 1. Extended Service Template Process

\begin{tabular}{|c|c|c|c|}
\hline Phase & Stage & Description & Origins of each phase/ stage \\
\hline & & $\begin{array}{l}\text { Joint agreement with client to use Extended } \\
\text { Service Template Process if deemed } \\
\text { appropriate }\end{array}$ & $\begin{array}{l}\text { Extended Service Template } \\
\text { Process }\end{array}$ \\
\hline $\mathbf{I}$ & & Participant selection & Service Template Process [1999] \\
\hline \multirow[t]{5}{*}{ II } & & $\begin{array}{l}\text { Service quality measurement and data } \\
\text { validation [for each group] }\end{array}$ & $\begin{array}{l}\text { Service Template Process [1994, } \\
\text { 1997] }\end{array}$ \\
\hline & 1 & Preparation & Service Template Process [1994] \\
\hline & 2 & Explore service characteristics & Service Template Process [1994] \\
\hline & 3 & $\begin{array}{l}\text { Plot perceptions and expectations against } \\
\text { identified characteristics on Service Template }\end{array}$ & Service Template Process [1994] \\
\hline & 4 & Interpret and validate issues & Service Template Process [1997] \\
\hline \multirow[t]{4}{*}{ III } & & Improvement agenda development & Service Template Process [1999] \\
\hline & 1 & $\begin{array}{l}\text { Brief participants, surface concerns and } \\
\text { refamiliarise }\end{array}$ & $\begin{array}{l}\text { Extended Service Template } \\
\text { Process }\end{array}$ \\
\hline & 2 & Explore and learn & $\begin{array}{l}\text { Extended Service Template } \\
\text { Process }\end{array}$ \\
\hline & 3 & Generate agenda for improvement & $\begin{array}{l}\text { Extended Service Template } \\
\text { Process }\end{array}$ \\
\hline
\end{tabular}




\section{Table 2. Case study organisations}

\begin{tabular}{|c|c|c|}
\hline Organisation & Service quality issue & Purposive samples \\
\hline $\begin{array}{l}\text { Large, multi-site public } \\
\text { service }\end{array}$ & $\begin{array}{l}\text { Main reception: } \\
\text { improvement to main reception on the } \\
\text { organisation's main site }\end{array}$ & $\begin{array}{l}\text { Service users: } \\
6 \text { internal staff representing key users of } \\
\text { reception services } \\
\text { Service deliverers: } \\
3 \text { reception staff; } \\
1 \text { departmental manager }\end{array}$ \\
\hline $\begin{array}{l}\text { New university business } \\
\text { school }\end{array}$ & $\begin{array}{l}\text { Dissertation supervision: } \\
\text { improvement to undergraduate business } \\
\text { management dissertation supervision } \\
\text { [separate data already collected from } \\
\text { students by questionnaire] }\end{array}$ & $\begin{array}{l}\text { Service users: } \\
8 \text { level III undergraduates } \\
\text { Service deliverers: } \\
6 \text { dissertation supervisors }\end{array}$ \\
\hline $\begin{array}{l}\text { International publishing } \\
\text { company }\end{array}$ & $\begin{array}{l}\text { Author - publisher relationship: } \\
\text { improvement to author support in the } \\
\text { ELT division }\end{array}$ & $\begin{array}{l}\text { Service users: } \\
2 \text { groups, each of } 4 \text { authors } \\
\text { Service deliverers: } \\
2 \text { groups, each of } 4 \text { commissioning } \\
\text { editors }\end{array}$ \\
\hline $\begin{array}{l}\text { Small businesses support } \\
\text { services provider }\end{array}$ & $\begin{array}{l}\text { Mentor training: } \\
\text { improvement to mentor training [separate } \\
\text { data collected from small business } \\
\text { owners by questionnaire] }\end{array}$ & $\begin{array}{l}\text { Service users: } \\
5 \text { trainee mentors } \\
\text { Service deliverers: } \\
1 \text { Business mentor trainer; } \\
2 \text { managers }\end{array}$ \\
\hline
\end{tabular}


Figure 1. Anatomy of a Service Template

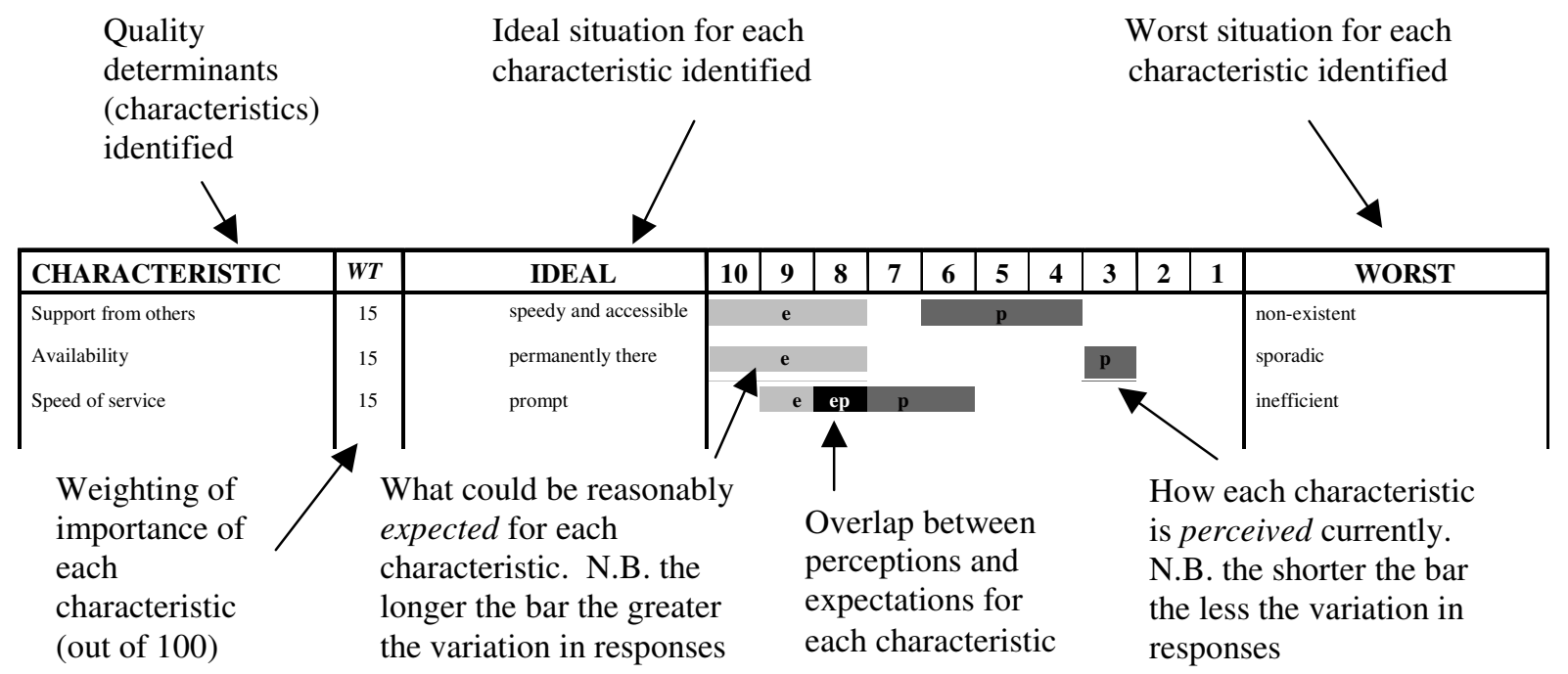


Figure 2 Extracts from Service Templates:

a. Internal users' perceptions and expectations of the Reception Service

\begin{tabular}{|c|c|c|c|c|c|c|c|c|c|c|c|c|c|}
\hline CHARACTERISTIC & $W T$ & IDEAL & 10 & 9 & 8 & 7 & 6 & 5 & 4 & 3 & 2 & 1 & WORST \\
\hline Location -appearance (physical) & 10 & welcoming and efficient & $\overline{\mathrm{e}}$ & & & & $\bar{p}$ & & & & & & cluttered and disorganised \\
\hline Environment -noise & 10 & soft and absorbed & & & e & & & & & & p & & echoes \\
\hline Environment -temperature & 10 & comfortable & & & & e & & & & p & & & cold and draughty \\
\hline Staffing -knowledge & 10 & $\begin{array}{r}\text { very knowledgeable about } \\
\text { whole organisation }\end{array}$ & & e & & & p & & & & & & in the dark \\
\hline Staffing -training & 10 & $\begin{array}{l}\text { able to deal with people and a } \\
\text { comprehensive range of query } \\
\text { strategies }\end{array}$ & & e & & p & & & & & & & lack of skills and strategies \\
\hline Role-switchboard & 10 & available to caller & & e & & & & & p & & & & engaged \\
\hline Role-counter & 10 & quickly available to visitor & & e & & & & & p & & & & queues \\
\hline Role -range of services & 10 & publicised and defined to users & e & & & & & & p & & & & what do they do? \\
\hline Information provision-currency & 10 & up to date & & e & & & $\mathbf{p}$ & & & & & & outdated \\
\hline Information provision -range & 10) & from all areas & & e & & & p & & & & & & limited \\
\hline Information provision -range & ) & regular and one off & & e & & & p & & & & & & sporadic \\
\hline Location-position in area & & prominent/obvious & & e & & & & p & & & & & tucked away \\
\hline Location - position on site & & at the main entrance & & & e & & & & p & & & & away from main routes \\
\hline Location-signage & & in yer face & e & & & & & & p & & & & where is it? \\
\hline
\end{tabular}

\section{b. Receptionists' perceptions and expectations of the Reception Service}

\begin{tabular}{|c|c|c|c|c|c|c|c|c|c|c|c|c|c|}
\hline CHARACTERISTIC & $W T$ & IDEAL & 10 & 9 & 8 & 7 & 6 & 5 & 4 & 3 & 2 & $\mathbf{1}$ & WORST \\
\hline $\begin{array}{l}\text { Support from others (knowledge } \\
\text { and cover) }\end{array}$ & 15 & speedy and accessible & & e & & & & p & & & & & non-existent \\
\hline Availability & 15 & permanently there & & e & & & & & & p & & & sporadic \\
\hline Speed of service & 15 & prompt & & e & ep & p & & & & & & & inefficient \\
\hline Quality time with users & 15 & all your attention & e & & & p & & & & & & & begrudged time \\
\hline Receptionist-knowledge & ) & correct and up to date & & e & & p & & & & & & & goldfish (3 second memory) \\
\hline Receptionist -appearance & 15 & smart and efficient & ep & & & & & & & & & & slovenly and tardy \\
\hline Receptionist-manner & ) & appropriate and confident & & ep & p & & & & & & & & offhand, floundering \& hesitant \\
\hline Reception desk -height & ) & user friendly and visible & & e & & & & p & & & & & obstructive and invisible \\
\hline Reception desk -acoustics & 15 & no distracting noises & & e & & & & & & & & p & can't hear \\
\hline Reception desk -user friendliness & | & accessible and visible & e & & & & & & p & & & & stuck in corner \\
\hline $\begin{array}{l}\text { Reception desk -physical } \\
\text { security of staff }\end{array}$ & ) & safe & e & & & & & & & & & p & vulnerable \\
\hline $\begin{array}{l}\text { How informed are visitors on } \\
\text { arrival? }\end{array}$ & 10 & accurate and full & & & & e & & & p & & & & non-existent \\
\hline Acknowledgement of user & & immediate & e & & p & & & & & & & & offhand \\
\hline $\begin{array}{l}\text { Level of training (for reception } \\
\text { work) }\end{array}$ & & ongoing and not reactive & & e & & & p & & & & & & in at the deep end \\
\hline
\end{tabular}

